\title{
Congestive heart failure: Treat the disease, not the symptom
}

\section{Return to normalcy/Part II-The experimental approach}

Gerald D. Buckberg, MD

See related article on page 1017.
From the Department of Surgery, David Geffen School of Medicine at the University of California-Los Angeles, Los Angeles, Calif.

Received for publication May 4, 2007; accepted for publication May 14, 2007.

Address for reprints: Gerald D. Buckberg, MD, David Geffen School of Medicine at UCLA, Department of Surgery, 10833 Le Conte Avenue, 62-258 CHS, Los Angeles, CA 90095 (E-mail: gbuckberg@mednet. ucla.edu).

J Thorac Cardiovasc Surg 2007;134:844-9

$0022-5223 / \$ 32.00$

Copyright $\odot 2007$ by The American Association for Thoracic Surgery

doi:10.1016/j.jtcvs.2007.05.053
$\mathrm{T}$ The report by Zhang and associates ${ }^{1}$ in this issue applies an important 3-dimensional magnetic resonance imaging (MRI) tagging method to demonstrate that altering ventricular geometry by using the Dor procedure (as they interpreted this operation) in sheep in congestive heart failure increases systolic circumferential shortening in remote muscle. These experimental changes document the clinical improvement in remote muscle function reported worldwide with left ventricular (LV) restoration. ${ }^{2,3}$ Such application of advanced imaging methods allows studies to focus on how interventions improve function by changing ventricular muscle deformation that occurs sequentially during the cardiac twisting motion. Furthermore, these regional functional data allow differentiation from nonfunctional remote regions that echocardiographic analysis shows are displaced without contracting, together with providing a time course for displaying how global function is affected by cardiac rebuilding.

\section{Normal and Abnormal Form}

The surgical approach to congestive heart failure, like other operative objectives, should treat the disease and not the symptom and return structures toward normal shape, as described by others, ${ }^{4}$ and this became the title of my 2001 Journal of Thoracic and Cardiovascular Surgery editorial. ${ }^{5}$ The geometric disease in ischemic dilated cardiomyopathy is the spherical chamber, which is different than the elliptical or conical normal heart shape (Figure 1). The symptom is the spherical chamber, whereby the normal helical chamber develops a more circular configuration thl at might flatten fiber orientation and alter performance. ${ }^{6,7}$

Despite imaging advantages, the experimental design of this study has a major flaw because baseline is ascribed to the infarction state rather than to the normal heart. The authors held fast to repeated requests to supplement their database with a design that introduces normality as a reconstructive guideline for operative interventions. It seems that, aside from supplying superb imaging technology, the surgical planning strategy must also recognize and codify normality (which exists before the infarction), show how disease distorts this (their preoperative control), identify how and why the intervention selected rebuilds normality, and relate results toward the limitations of the selected procedure. For example, if normality was not recaptured, the discussion should identify whether this is a problem with the operative method or related to the timing of postoperative measurements.

\section{Border and Remote Muscle}

Prior studies addressed the peri-infarction border zone, showing that the issue was impaired contractile function rather than increased wall stress, ${ }^{8}$ and directed 


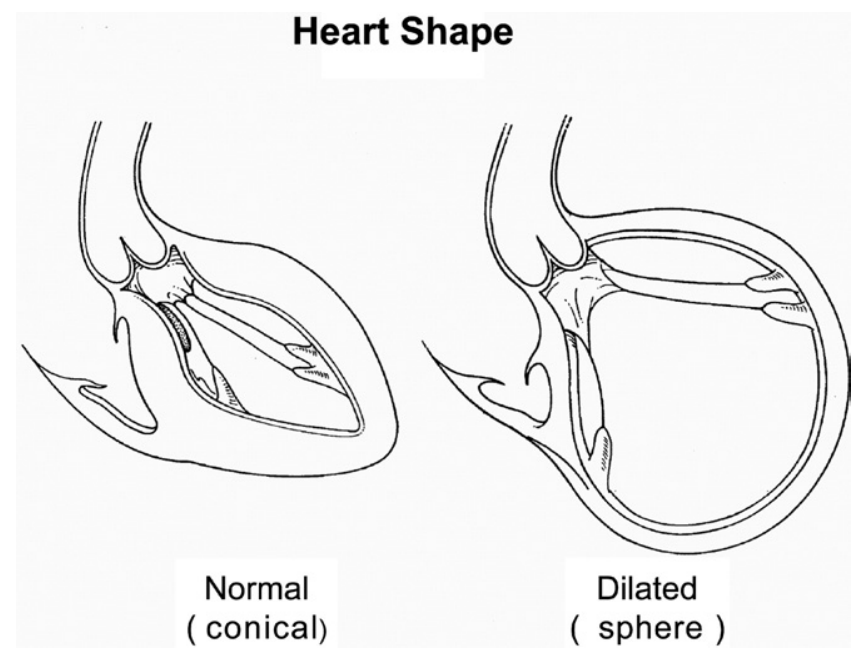

Figure 1. The left image shows cardiac shape in the normal heart with a conical or elliptical chamber. The right image shows a dilated failing heart with a spherical shape.

less attention toward the remote muscle that rapidly impairs function after anterior wall infarction in relation to ventricular shape. ${ }^{9}$ The tagging study in 2000 by Bogaert and associates ${ }^{9}$ introduced the key link whereby border and remote muscle zones become combined culprits for dysfunction after ventricular volume is increased by anterior infarction. The study by Zhang and colleagues ${ }^{1}$ coalesces these data and is helpful in directing the attention of cardiologists and surgeons toward malfunction of global muscle, the recovery of which is quantified by returning deformation of the less efficient stretched muscle toward normal shape after ventricular restoration.

Kramer and coworkers, ${ }^{10}$ in 2002, followed Bogaert and associates' approach ${ }^{9}$ and used tagging methods to quantify remote muscle circumferential shortening improvement after restoration, compared the changes to control studies, showed this spatial configuration change (Figure 2, A), ${ }^{10}$ and adhered to the aforementioned surgical study planning concept. Similar findings of remote muscle circumferential deformation improvement were recently reported by Carmichael and associates ${ }^{11}$ at the Cleveland Clinic. Editorial suggestions to include this information were not followed, so that a restricted background analysis underlies the article's introductory statements about prior study limitations. Furthermore, nonMRI studies by Taniguchi and colleagues ${ }^{12}$ codified improved velocity of remote muscle circumferential fiber shortening; showed that regional stress, function, and remodeling improve after aneurysmectomy; and also demonstrated that these results were not achieved by means of coronary artery bypass grafting alone, thereby answering the introduction's supposition that confounding effects of other procedures had not yet been addressed.

\section{Dilemma of Abnormal Shape}

Failure to achieve normal shape is the foundation of the limitations of a host of nonreconstructive congestive heart failure therapies, such as coronary artery bypass grafting, mitral valve rebuilding in ischemic cardiomyopathy, biventricular pacing, defibrillator devices, and a spectrum of pharmacologic treatments that alter neuroendocrine factors yet exclude addressing the scar nidus that underlies subsequent remote ventricular stretch. The sphere was retained in this study (Figure 2, B), although it was slightly less circular. It seems the surgical objective should be to restore normality rather than making the heart "less sick."

Certainly, the investigator is free to design each study and set goals that relate to how rebuilding improves function through the Starling relationship. However, the analysis should also echo the relationship of these objectives toward (1) how their "Dor procedure" reproduces what was initially described and (2) definition of mechanisms that allow observed function to improve. Their goal of 50\% surgical neck reduction to increase regional strain was achieved but differs from Dor's objectives (to whom this operation is ascribed) that indicate "the endoventricular suture helps restore the curvature towards its shape before infarction, and helps in selection of the size, shape and orientation of the patch."

These limitations are evident when current results in Figure 2, $B$, are compared with the clinical findings of Kramer in Figure 2, $A,{ }^{10}$ who also included preoperative normal configurations for comparison. Although the circular configurations are evident during infarction, a similar but slightly less spherical shape followed this experiment, whereas the normal conical shape was achieved after clinical LV reconstruction. Editorial suggestions to include an image of the control natural ventricular shape were declined; inclusion of such a normal elliptical shape would (1) allow contrast with the circular or spherical chamber that develops after infarction, (2) demonstrate that the spherical configuration is relatively retained after experimental patch placement, (3) potentially permit the authors and readers to question the role of geometry in determining function, and (4) possibly generate questions about what function could be expected if the rebuilding procedure reconstructed the normal elliptical form rather than a smaller sphere. 
Pre - op

A

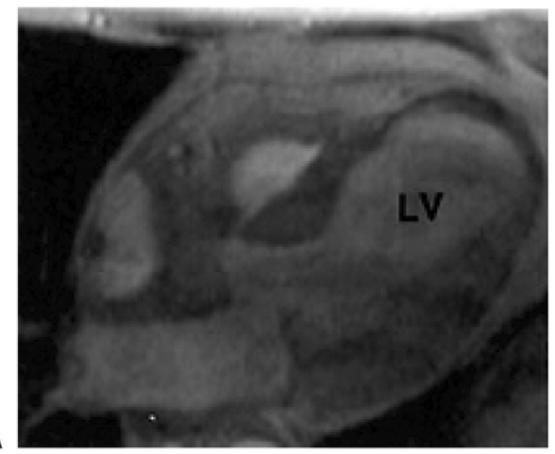

B

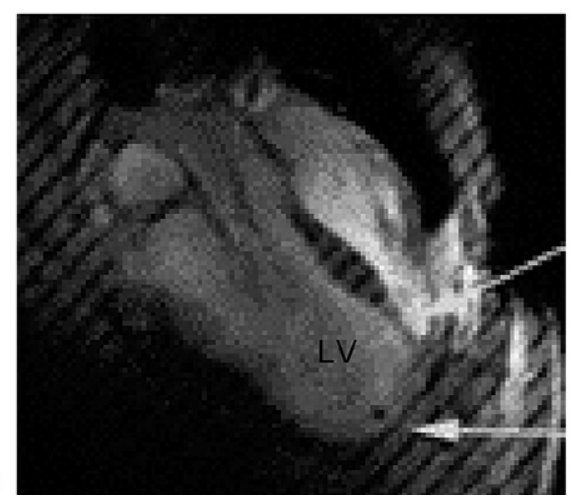

Post - op
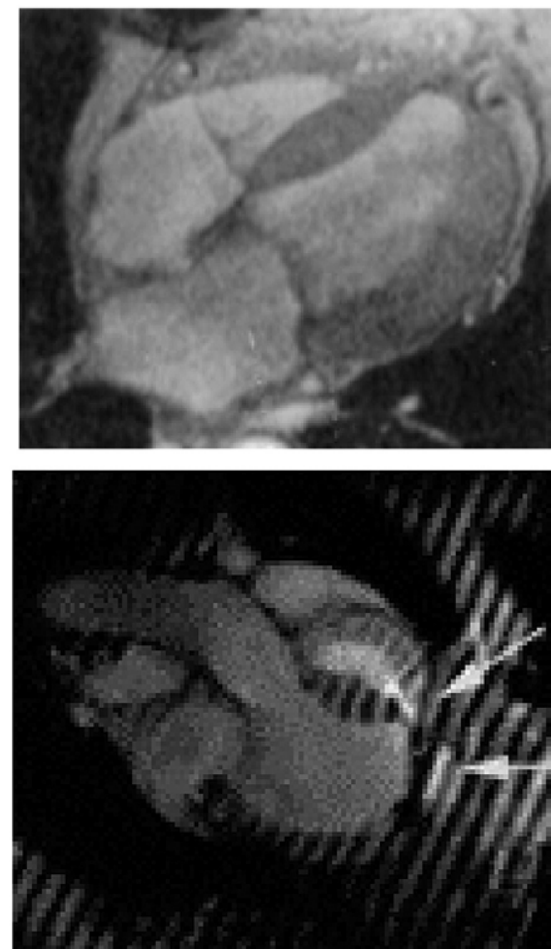

Figure 2. A, The left image shows a spherical dilated cardiac patient with an anterior infarction taken from the 2002 MRI tagging report by Kramer and associates. ${ }^{10}$ The right image shows how left ventricular rebuilding restored a conical left ventricular shape. $B$, The left image shows the experimental postinfarction shape appearing in the report by Zhang and colleagues, ${ }^{1}$ displaying the same spherical preoperative cardiac shape appearing in panel $A$, which displays the preoperative clinical image. The right image in panel B shows that the postoperative volume is reduced, but the cardiac shape remains spherical and continues to mirror the left image's preoperative configuration in both the clinical and experimental studies. Pre-op, Preoperative; Post-op, postoperative; $L V$, left ventricle.

\section{Importance of Normal Shape}

Unfortunately, the article's statement that no one knows about optimal postoperative shape skirts away from the beauty of understanding and driving toward rebuilding the normal shape. Advantages of this configuration are evident from the tagging MRI studies of Bogaert and Rademakers, ${ }^{13}$ which demonstrated regional nonuniformity of the normal left ventricle, whereby deformation is accentuated as sequential normal heart motion progresses from the base to the apex. Consequently, the stated "idealized LV wall geometry as a hemispherical shell" does not exist in the conical heart, and their relatively spherical-shaped end point after LV rebuilding (Figure 1, $B$ ) is clinically described as a less ideal spherical box-like chamber. ${ }^{14}$

Reconstruction of a more normal elliptical shape aims toward Dor's objective of returning configuration toward its shape before infarction and underlies the development of clinically used shaping devices and conically shaped mandrels. ${ }^{15}$ This normal form-related end point has led to placing the oblique patch above the scar to reconstruct normal shape,${ }^{16}$ as well as repeating this intervention in ischemic nonscarred septal muscle in dilated failing hearts in Russia ${ }^{17}$ with similarly improved late results to those after scar exclusion, and underlies a recently posed question: "Is the goal to exclude the disease or to rebuild form ?" ${ }^{18}$ Decisions toward this goal (Figure 3$)^{18}$ evolved from recognizing higher late mortality in Dor's long-term experience $^{19}$ after a larger chamber was retained when excluding the scar was the anatomic reconstruction end point. These selection criteria led to postoperative retention of more dilated remote muscle and portended higher late mortality because volume is the surrogate for survival after ischemic cardiac dilation. ${ }^{20}$

Conceivably, the sphere-shaped end point and functional results in this study might become the starting point for a new procedure if these results are subsequently compared against rebuilding a conical chamber. If this approach is selected, new data that also include control normal tagging data could simultaneously test how the each procedure restored normal function.

\section{Influence of Shape on Function}

The current recommendation to use a patch differs from concepts that nonpatch methods are preferable. One potential reason for this selection includes reduction of wall tension during patch placement into the fragile muscle within an akinetic segment containing a trabecular scar. I suspect ventricular shape will become the vital surgical consideration, but subsequent functional studies are needed to determine whether such decisions are related to 


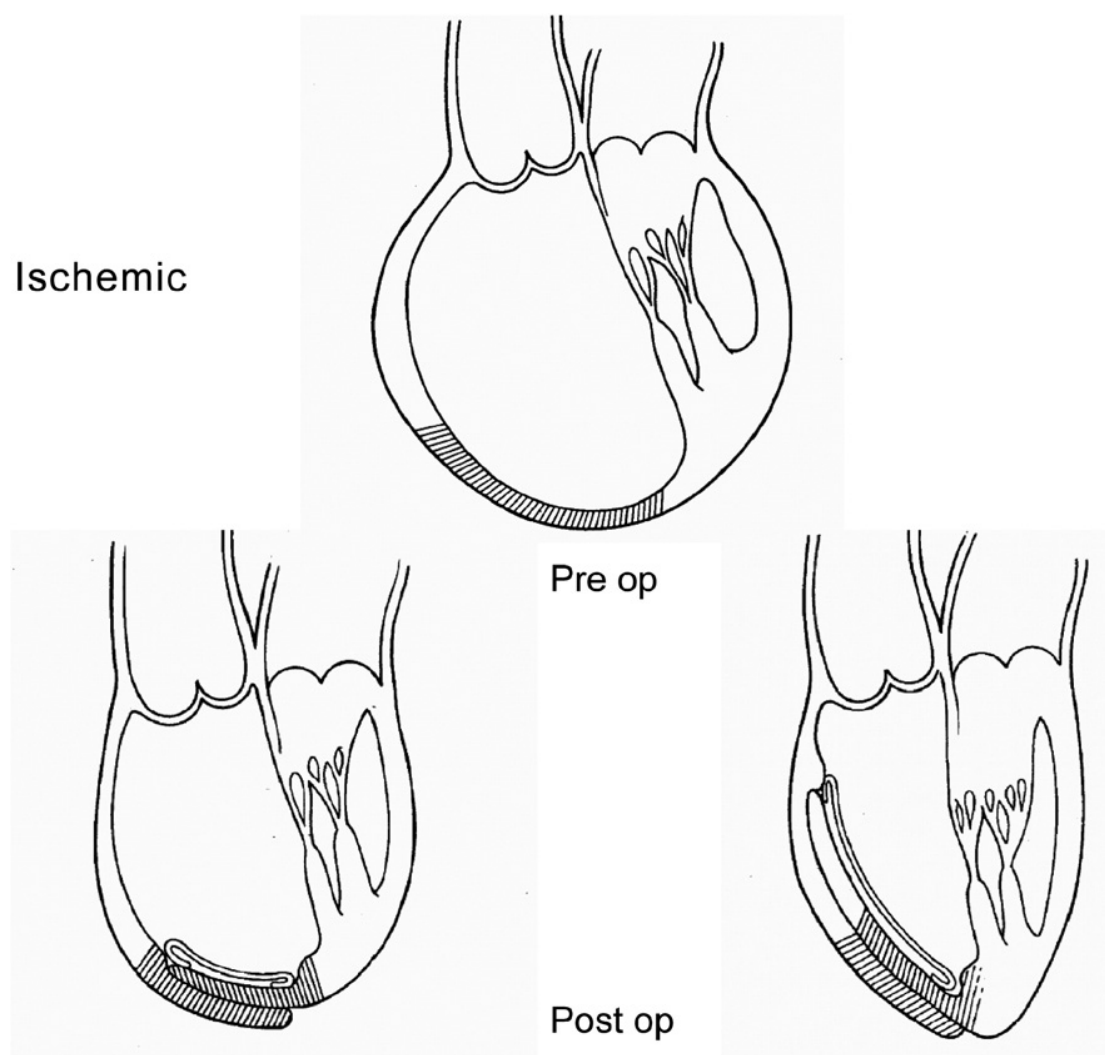

Figure 3. Comparison of treatment of dilated ischemic cardiomyopathy (top) by addressing the disease (lower left) and leaving a spherical shape or doing the septal anterior ventricular exclusion operation or Pacopexy ${ }^{17}$ (lower right) and rebuilding an elliptical shape. Note that the patch is placed into the septum that does not have a scar, and the point of placement is above the scarred region in the midseptum. Pre op, Preoperative; Post op, postoperative.

Post op

patches (Dacron, pericardium, or a flap of transmurally scarred muscle) or ventricular form. The normal elliptical spatial configuration relates to how the remaining fibers are oriented, and my suspicion is that creating a geometric change in fiber direction toward normal shape will become the end point that defines ultimate functional recovery.

The authors document how reconstruction changes in systolic and diastolic volume and comment on how it affects the Starling relationship. A form-function relationship exists, and therefore the shape influence on fiber orientation will effect function at rest and during exercise, as shown by Sallin ${ }^{6}$ and Ingels. ${ }^{7}$ This investigative team previously used diffusion tensor MRI analysis to determine whether the helical fiber orientation of the normal heart geometry is changed when this model of heart failure dilates the ventricle and rebuilds cardiac structure after restoration. ${ }^{21}$ A control group was included in that study to properly respond to my principal objection to this report, but that report evaluated the unloaded, decompressed, nonfunctioning heart and thus failed to determine (1) whether the stretch of disease changed fiber direction and (2) whether rebuilding could restore the natural helical design that underlies the living heart's function. ${ }^{22}$
A basic anatomic concept of heart failure is that the dilated heart becomes spherical through a change in the radius of curvature within the ventricular wall. The currently reported functional analysis of improvement in remote muscle systolic circumferential shortening implies the authors might consider repeating their prior MRI study and reanalyzing the data using the reported dilated chamber dimensions. Such a study would determine whether the normal helical configuration is changed by infarction and restored by $\mathrm{LV}$ rebuilding, as well as whether changes from an elliptical to a spherical fiber orientation altered function, and then determine whether changing fiber orientation would further improve deformation.

\section{Recovery Timing Evaluation}

The discussion suggests evaluations at a longer than 6-week recovery period might be needed, and subsequent changes might relate to repair of the collagen sheathing of myocytes, where the half-life of collagenase is 120 days. ${ }^{23}$ Recovery of neuroendocrine markers toward normal values after longer intervals after ventricular volume reduction by means of $\mathrm{LV}$ restoration were recently reported from the Cleveland Clinic ${ }^{24}$ and Japan. ${ }^{25}$ Timing 
of functional evaluation might have an important effect because withdrawal of these neuroendocrine adaptive forces after stretching might explain the reported clinical change of pressure-volume relationships after 4 months of decompression in a study that did not collect biochemical values. ${ }^{26}$ Perhaps future studies might harvest these biochemical markers at longer follow-up intervals and compare them against the current spherical postoperative shape and against rebuilding a more conical configuration, as shown in Figure 2, and thus become a surrogate for avoiding more complex functional tests.

The role of LV rebuilding is linked to clinical recovery, and these results are consistent with reports showing New York Heart Association status and 6-minute walking test improvement. ${ }^{3,27}$ Consequently, the authors' concluding comment that their study is the first to show that the Dor procedure does anything seems a bit cavalier, especially because similar functional clinical findings were reported by Taniguchi and associates ${ }^{28}$ in 1999, Kramer and coworkers ${ }^{10}$ in 2002, and Carmichael and colleagues ${ }^{24}$ from the Cleveland Clinic in 2006. Ventricular shape should be considered with these changes in volume because energy demands increase with exercise, and stress is related to dimensional changes. Consequently, the radius of curvature underlying wall stress increases and is related to $\pi \mathrm{R}^{3}$ in a spherical chamber but to $\pi \mathrm{R}^{2}$ in a cylinder. Conversely, wall stress decreases in the conical heart; deformation increases and efficiency improves while muscle size anisotropically thickens as chamber dimension narrows toward the apex.

In conclusion, the starting point for evaluation for recovery must arise in the normal heart and not the damaged heart. This initiates with understanding normal form and function and avoiding comparisons against the wrong anatomy. This comparison initiates from a proper control database so that the investigator and reader can understand that valid results garnered from starting with a sphere (which is the disease) and subsequently generated by a smaller sphere (after restoration) convey an abnormal geometry-based end point. Returning toward normal shape in both the operating room and the experimental laboratory will yield evaluation measurements that more closely define how our interventions work.

\section{References}

1. Zhang P, Guccione JM, Nicholas S, Walker J, Crawford P, Shamal A, et al. Endoventricular patch plasty for dyskinetic anteroapical left ventricular aneurysm increases systolic circumferential shortening in sheep. J Thorac Cardiovasc Surg. 2007;134:1017-24.

2. Dor V, Di Donato M, Sabatier M, Montiglio F, Civaia F. Left ventricular reconstruction by endoventricular circular patch plasty repair: a 17-year experience. Semin Thorac Cardiovasc Surg. 2001;13:43547 .

3. Athanasuleas CL, Buckberg GD, Stanley AW, Siler W, Dor V, Di Donato M, et al. Surgical ventricular restoration in the treatment of congestive heart failure due to post-infarction ventricular dilation. J Am Coll Cardiol. 2004;44:1439-45.

4. Bernard C. An introduction to the study of experimental medicine. New York: Dover Publications; 1957.

5. Buckberg GD. Congestive heart failure: treat the disease, not the symptom-return to normalcy. J Thorac Cardiovasc Surg. 2001;121: 628-37.

6. Sallin EA. Fiber orientation and ejection fraction in the human ventricle. Biophys J. 1969;9:954-64.

7. Ingels NB Jr. Myocardial fiber architecture and left ventricular function. Technol Health Care. 1997;5:45-52.

8. Guccione JM, Moonly SM, Moustakidis P, Costa KD, Moulton MJ, Ratcliffe MB, et al. Mechanism underlying mechanical dysfunction in the border zone of left ventricular aneurysm: a finite element model study. Ann Thorac Surg. 2001;71:654-62.

9. Bogaert J, Bosmans H, Maes A, Suetens P, Marchal G, Rademakers FE. Remote myocardial dysfunction after acute anterior myocardial infarction: impact of left ventricular shape on regional function: a magnetic resonance myocardial tagging study. J Am Coll Cardiol. 2000;35:1525-34

10. Kramer CM, Magovern JA, Rogers WJ, Vido D, Savage EB. Reverse remodeling and improved regional function after repair of left ventricular aneurysm. J Thorac Cardiovasc Surg. 2002;123:700-6.

11. Carmichael BB, Setser RM, Stillman AE, Lieber ML, Smedira NG, McCarthy PM, et al. Effects of surgical ventricular restoration on left ventricular function: dynamic MR imaging. Radiology. 2006;241: 710-7.

12. Taniguchi K, Sakurai M, Takahashi T, Imagawa H, Mitsuno M, Nakano S, et al. Postinfarction left-ventricular aneurysm: regional stress, function, and remodeling after aneurysmectomy. Thorac Cardiovasc Surg. 1998;46:253-9.

13. Bogaert J, Rademakers FE. Regional nonuniformity of normal adult human left ventricle. Am J Physiol Heart Circ Physiol. 2001;280: H610-20.

14. Athanasuleas CL, Buckberg GD, Menicanti L, Gharib M. Optimizing ventricular shape in anterior restoration. Semin Thorac Cardiovasc Surg. 2001; 13:459-67.

15. Menicanti L, Di Donato M. The Dor procedure: what has changed after fifteen years of clinical practice? J Thorac Cardiovasc Surg. 2002; 124:886-90.

16. Isomura T, Horii T, Suma H, Buckberg G. Septal anterior ventricular exclusion operation (Pacopexy) for ischemic dilated cardiomyopathy; treat form not disease. Eur J Cardiothorac Surg. 2006;29(suppl 1): S245-50.

17. Bockeria L, Gorodkov A, Dorofeev A, Alshibaya M, Buckberg GD. Left ventricular geometry reconstruction in ischemic cardiomyopathy patients with predominantly hypokinetic left ventricle. Eur J Cardiothorac Surg. 2006;29(suppl 1):S251-8.

18. Buckberg GD, RESTORE Group. Form versus disease: optimizing geometry during ventricular restoration. Eur J Cardiothorac Surg. 2006;29(suppl 1):S238--S244.

19. Di Donato M, Toso A, Maioli M, Sabatier M, Stanley AW Jr, Dor V, et al. Intermediate survival and predictors of death after surgical ventricular restoration. Semin Thorac Cardiovasc Surg. 2002;13:46875 .

20. White HD, Norris RM, Brown MA, Brandt PW, Whitlock RM, Wild CJ. Left ventricular end-systolic volume as the major determinant of survival after recovery from myocardial infarction. Circulation. 1987; 76:44-51

21. Walker JC, Guccione JM, Jiang Y, Zhang P, Wallace AW, Hsu EW, et al. Helical myofiber orientation after myocardial infarction and left ventricular surgical restoration in sheep. J Thorac Cardiovasc Surg. 2005;129:382-90.

22. Buckberg GD. Imaging, models, and reality: a basis for anatomicphysiologic planning. J Thorac Cardiovasc Surg. 2005;129:243-5.

23. Caulfield JB, Janicki JS. Structure and function of myocardial fibrillar collagen. Technol Health Care. 1997;5:95-113.

24. Carmichael BB, Setser RM, Stillman AE, Lieber ML, Smedira NG, McCarthy PM, et al. Effects of surgical ventricular restoration on left ventricular function: dynamic MR imaging. Radiology. 2006;241: 710-7. 
25. Suma H, Isomura T, Horii T, Buckberg G, RESTORE Group, Role of site selection for left ventriculoplasty to treat idiopathic dilated cardiomyopathy. Heart Fail Rev. 2005;9:329--336.

26. Levin HR, Oz MC, Chen JM, Packer M, Rose EA, Burkhoff D. Reversal of chronic ventricular dilation in patients with end-stage cardiomyopathy by prolonged mechanical unloading. Circulation. 1995;91:2717-20.
27. Sartipy U, Anders ALD. Improved health-related quality of life and functional status after surgical ventricular restoration. Ann Thorac Surg. 2007;83:1381-7.

28. Taniguchi K, Sakurai M, Takahashi T, Imagawa H, Mitsuno M, Nakano S, et al. Postinfarction left-ventricular aneurysm: regional stress, function, and remodeling after aneurysmectomy. Thorac Cardiovasc Surg. 1998;46:253-9.

\section{ON THE MOVE?}

\section{Send us your new address at least six weeks ahead}

Don't miss a single issue of the journal! To ensure prompt service when you change your address, please photocopy and complete the form below.

Please send your change of address notification at least six weeks before your move to ensure continued service. We regret we cannot guarantee replacement of issues missed due to late notification.

\section{JOURNAL TITLE:}

Fill in the title of the journal here.

\section{OLD ADDRESS:}

Affix the address label from a recent issue of the journal here.

\section{NEW ADDRESS:}

Clearly print your new address here.

Name

Address

City/State/ZIP

\section{COPY AND MAIL THIS FORM TO:}

Elsevier Inc.

Subscription Customer Service

6277 Sea Harbor Dr

Orlando, FL 32887
OR FAX TO:

407-363-9661

OR E-mail:

elspcs@elsevier.com
OR PHONE:

800-654-2452

Outside the U.S., call

407-345-4000 